\title{
Thoracoscopic microsurgical excision of herniated thoracic discs
}

\author{
Daniel Rosenthal, M.D., and Curtis A. Dickman, M.D.
}

Division of Neurological Surgery, Barrow Neurological Institute, Phoenix, Arizona; and Division of Neurosurgery, Klinikumber Johann Wolfgang Goethe Universität, Frankfurt, Germany

Object. The authors began using thoracoscopy to treat pathological conditions of the spine in 1992. In this study they delineate their clinical experience in which this procedure was used to resect herniated thoracic discs.

Methods. Fifty-five patients underwent thoracoscopy for the resection of herniated thoracic discs. Thirty-six patients presented with myelopathies and 19 with incapacitating thoracic radicular pain. Forty-three patients underwent a single-level, 11 a two-level, and one a three-level discectomy. The mean operative time for thoracoscopic microdiscectomy was 3 hours and 25 minutes (range 80-542 minutes) and the mean blood loss was $327 \mathrm{ml}$ (range 124-1500 ml). Compared with thoracotomy, which was performed in 18 patients, thoracoscopy was associated with a mean of 1 hour less operative time and less than one-half of the blood loss, duration of chest tube drainage, usage of pain medication, and length of hospitalization. Compared with costotransversectomy, which was performed in 15 patients, thoracoscopy permitted more complete resection of calcified and midline thoracic discs because it provided a direct view of the entire anterior surface of the dura. Thoracotomy was associated with a significantly greater incidence of prolonged, disabling intercostal neuralgia compared with the mild transient episodes of intercostal neuralgia associated with thoracoscopy (50\% compared with 16\%). Thoracotomy also was associated with a significantly higher incidence of postoperative atelectasis and pulmonary dysfunction than thoracoscopy (33\% compared with 7\%). Clinical and neurological outcomes were excellent (mean follow-up period 15 months). Among the 36 myelopathic patients, 22 completely recovered neurologically; five improved functionally but had some residual myelopathic symptoms; and nine stabilized. Among the 19 patients with isolated thoracic radiculopathies, 15 recovered completely; four improved moderately; and none had worsened radicular pain.

Conclusions. Thoracoscopic microdiscectomy is a reliable surgical technique that can be performed safely with excellent clinical and neurological results.

Key Words * thoracoscopy * endoscopic spine surgery * herniated thoracic disc * thoracoscopic spine surgery * thoracic radiculopathy * thoracic myelopathy

Thoracoscopy is an anterior transthoracic endoscopic approach to the thoracic cavity and mediastinum. 
In cardiothoracic and spine surgery, this technique has become a well-established, valuable surgical approach because it is associated with less morbidity and more rapid recoveries than thoracotomy.[1,8,9,14,15,17,20,23-25,33,34,39] We began using thoracoscopy to treat pathological conditions of the thoracic spine in 1992. This report delineates our clinical experience using thoracoscopy to resect herniated thoracic discs in 55 patients.

\section{CLINICAL MATERIAL AND METHODS}

The clinical characteristics, operative results, and clinical outcomes of patients treated for herniated thoracic discs at our institutions were reviewed retrospectively. Patients' records, clinical examinations, diagnostic imaging studies, operative records, hospital charts, and office records were reviewed. Follow-up review consisted of evaluating postoperative radiographs and imaging studies of the surgical site to assess the decompression, follow-up office visits with clinical examinations, and telephone interviews.

\section{Patient Population}

Between 1992 and 1996, at our two tertiary clinical referral centers 55 consecutive patients underwent video-assisted thoracoscopy for treatment of herniated thoracic discs. There were 33 men and 22 women (mean age 48 years; range 31-72 years). Thirty-six patients presented with myelopathic signs and symptoms from spinal cord compression and 19 patients had incapacitating thoracic radicular pain without myelopathy. The mean preoperative duration of symptoms was 13 months (range 4 months-20 years).

Between 1986 and 1996, the same data were collected in patients at our facilities who underwent a costotransversectomy or a thoracotomy for the treatment of herniated thoracic discs. The 18 patients treated with thoracotomy and the 15 patients treated with costotransversectomy had similar clinical characteristics and severity of neurological deficits as the patients treated with thoracoscopy.

Preoperatively, the only clinical differences between patients treated thoracoscopically and those treated via a costotransversectomy were that the latter tended to have small or medium-sized discs that were focal and eccentric toward one side of the spinal canal. In this group, a higher proportion of patients also had radiculopathy without myelopathy. Like the patients who underwent thoracoscopy, the patients who underwent thoracotomy had larger discs, broad-based central discs, and calcified discs. They also had a higher incidence of more severe myelopathy than the patients who underwent costotransversectomy. Two patients treated with thoracotomy were originally intended to undergo thoracoscopy. One had tracheal stenosis and a double-lumen endotracheal tube could not be inserted. One had undergone a prior thoracotomy and had dense pleural adhesions that prohibited an endoscopic approach.

\section{Surgical Technique: Thoracoscopic Microsurgical Discectomy}

The general details of thoracoscopy for spinal exposure and dissection have been reported elsewhere.[10-12,42] Only the most salient details of the operative technique are discussed here.

The patient was placed in a lateral decubitus position with the side of access turned upward; the ventilated lung was positioned dependently. Before the patient was prepared for surgery, a C-arm was used to localize the level of disease and a mark was made to identify the skin over the pathological site and the sites where the portals were to be inserted. 
After the patient's skin was scrubbed, the portals and endoscope were inserted, and the lung was mobilized from the anterior surface of the spine. The ribs were counted internally to identify the disc space, and the pleura over the identified rib head was cauterized. The $\mathrm{C}$-arm was used to count the ribs, beginning caudally at the 12 th rib, to confirm the operative site. The ribs were counted several times to ensure that the correct level was identified. A tool or needle was held at the level of the disc to confirm the localization. The pleura was incised over the proximal rib and disc space and then mobilized. Its edges were folded laterally to expose the disc space, proximal rib, and adjacent segmental vessels.

The segmental vessels that supply the foramen and the rib at the level of disease were mobilized and usually ligated prophylactically to prevent bleeding. The segmental artery and vein were ligated with hemoclips and sharply transected with endoscopic scissors. The neurovascular bundle was detached from the undersurface of the rib by using subperiosteal dissection with curettes and periosteal elevators. Any bleeding from the neurovascular bundle was controlled with bipolar cauterization. If the aorta was displaced laterally, interfering with access to the disc space, the vessel was mobilized anteriorly after several sets of segmental vessels were ligated.

The proximal $2 \mathrm{~cm}$ of the rib and pedicle were removed to expose the spinal canal to visualize the lateral surface of the dura. The neurovascular bundle, intercostal muscles, and costotransverse and costovertebral ligaments were detached from the rib by using periosteal elevators and rib dissectors. The rib was transected and the bone was saved in case graft material was needed. Typically, we do not fuse a routine thoracic discectomy because it does not appear to destabilize the spine.[6] However, if a corpectomy was needed for exposure, a fusion was considered for reconstruction.[13]

The pedicle caudal to the disc space was identified and the foraminal ligaments were cut from its superior edge. The pedicle was removed by using a Kerrison rongeur, exposing the epidural space (Fig. 1). Early identification of the dura allowed the surgeon to visualize the anterolateral border of the spinal canal and enabled constant visual orientation to the position of the spinal cord during any subsequent dissection. Proper orientation is critical to perform the decompression safely. 


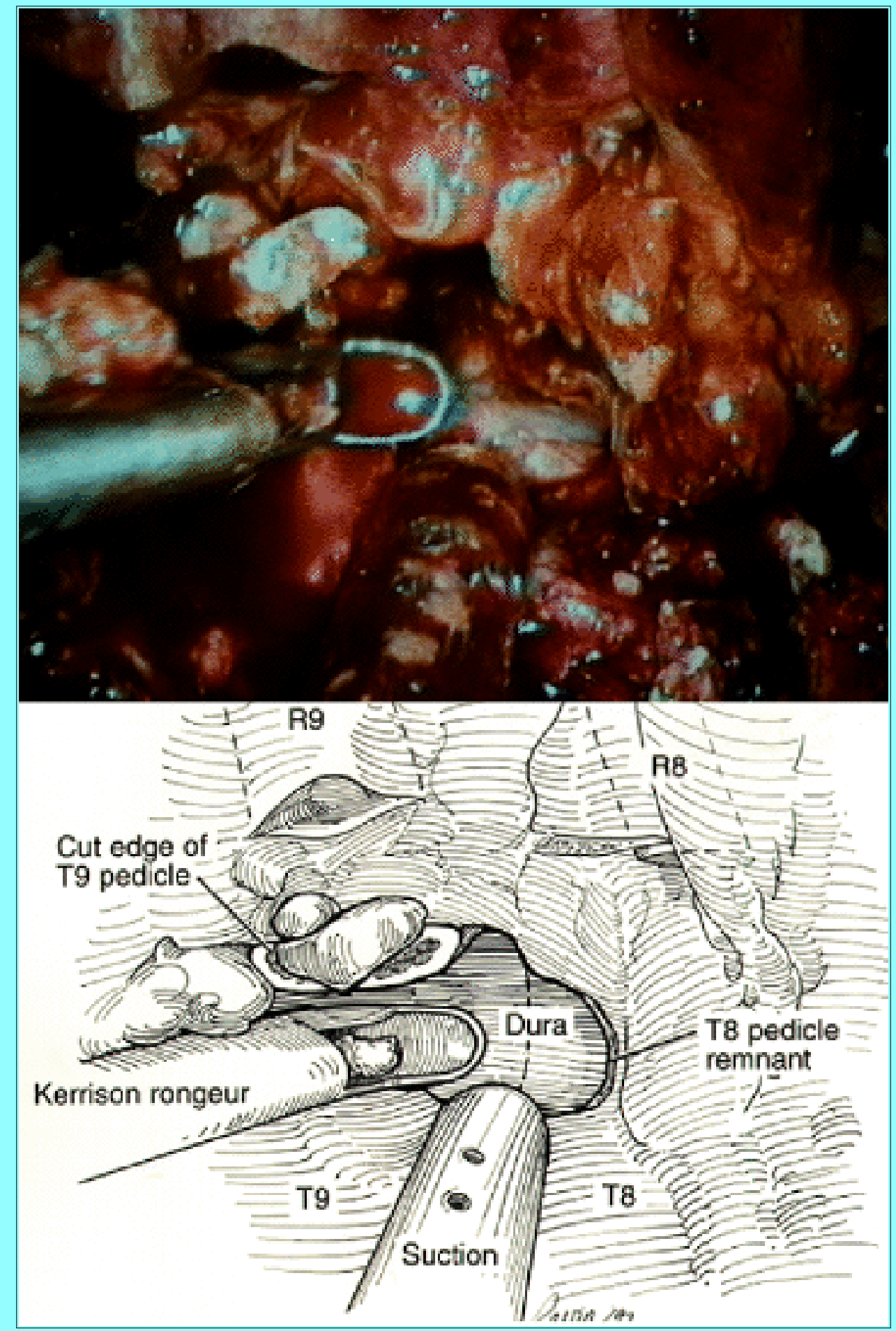

Fig. 1. Intraoperative photograph (upper) and illustration (lower) showing a right-sided approach to perform a T8-9 endoscopic microdiscectomy exposure. The rib head and pedicle are removed to expose the dura. The surgeon can then directly and safely visualize the remainder of the disc dissection in relationship to the position of the spinal cord.

The next surgical step is also critical: the creation of an empty cavity in the dorsal disc space and adjacent vertebral bodies that provides enough room to move the compressive disc material away from the epidural space. A sufficiently large cavity is mandatory to preserve neurological function. This working space minimized the entry of tools into the compressed epidural space; the surgeon could use the edges of fine microsurgical tools to pull the disc material away from the spinal cord and into the cavity. The cavity should be wide enough so that it extends cephalad and caudal to the disc herniation so 
the surgeon can visualize normal dura above and below the pathological site. The cavity should be deep enough to expose the entire ventral surface of the dura across the spinal canal to the medial border of the contralateral pedicle (Fig. 2).

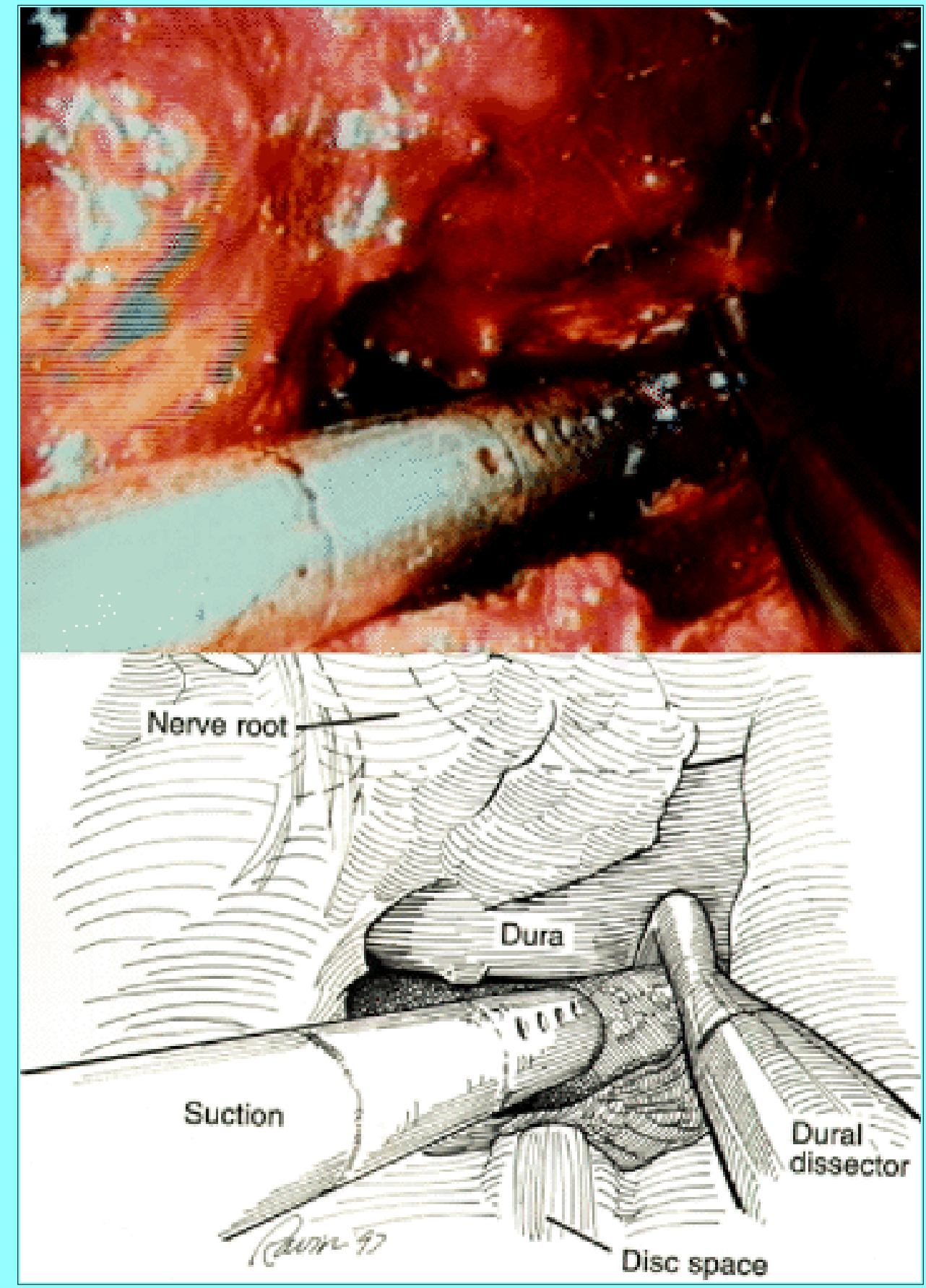

Fig. 2. Intraoperative photograph (upper) and illustration (lower) showing the anatomy during a left-sided thoracoscopic approach to remove a T5-6 disc hernation. A pyramidal cavity is created in the vertebral body to provide a working space and to expose the entire ventral surface of the dura. The disc herniation is completely resected. An endoscopic microdissection tool is palpating the ventral spinal canal to verify that the decompression is complete.

For the treatment of small or moderate-sized thoracic disc herniations or soft disc herniations, the working cavity was shaped like a pyramid (Fig. 3). To expose large discs, ossified discs, or intradural discs, much more room was needed. In fact, a corpectomy was required (Fig. 4). 


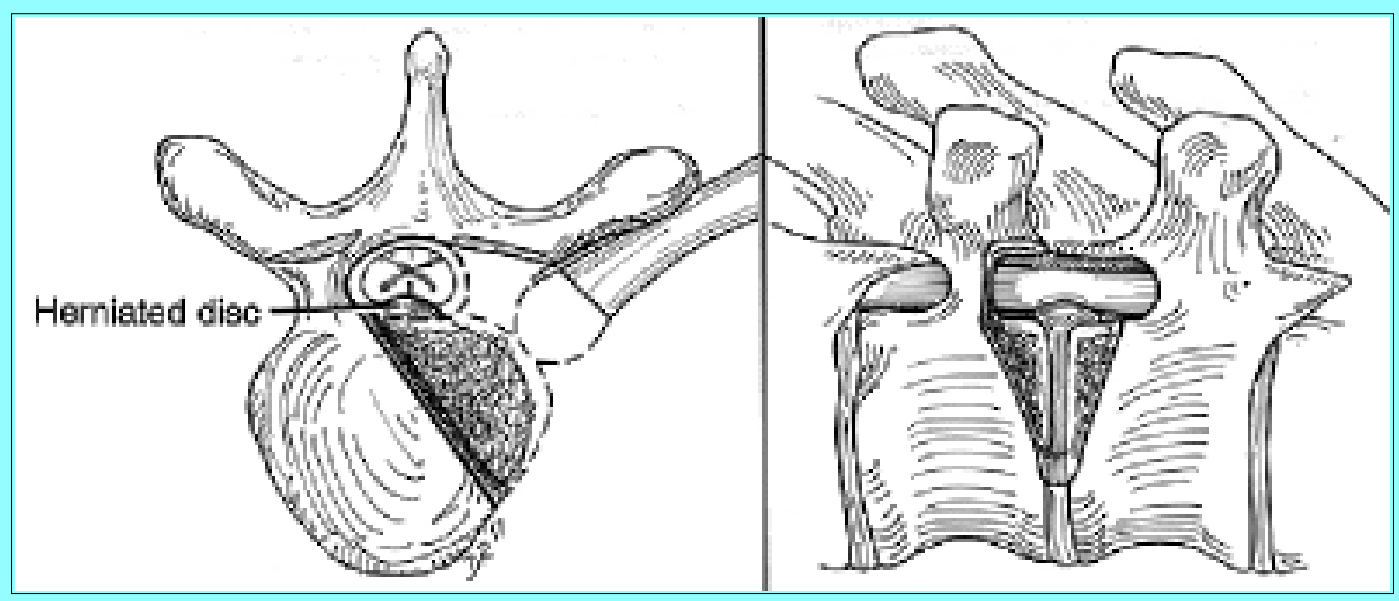

Fig. 3. Left: Illustration showing that a pyramidal cavity is created in the dorsal disc space and vertebral bodies to resect small or moderate-sized disc herniations. The rib head and pedicle are removed to expose the lateral dura. Next, a cavity is created in the vertebral bodies to expose the entire ventral spinal canal for the safe decompression of the spinal cord. Right: Lateral view showing that the cavity provides enough room to insert the tools without the need to place any objects in the compromised epidural space. If a small cavity is made, spinal stability is preserved and a fusion is not necessary.

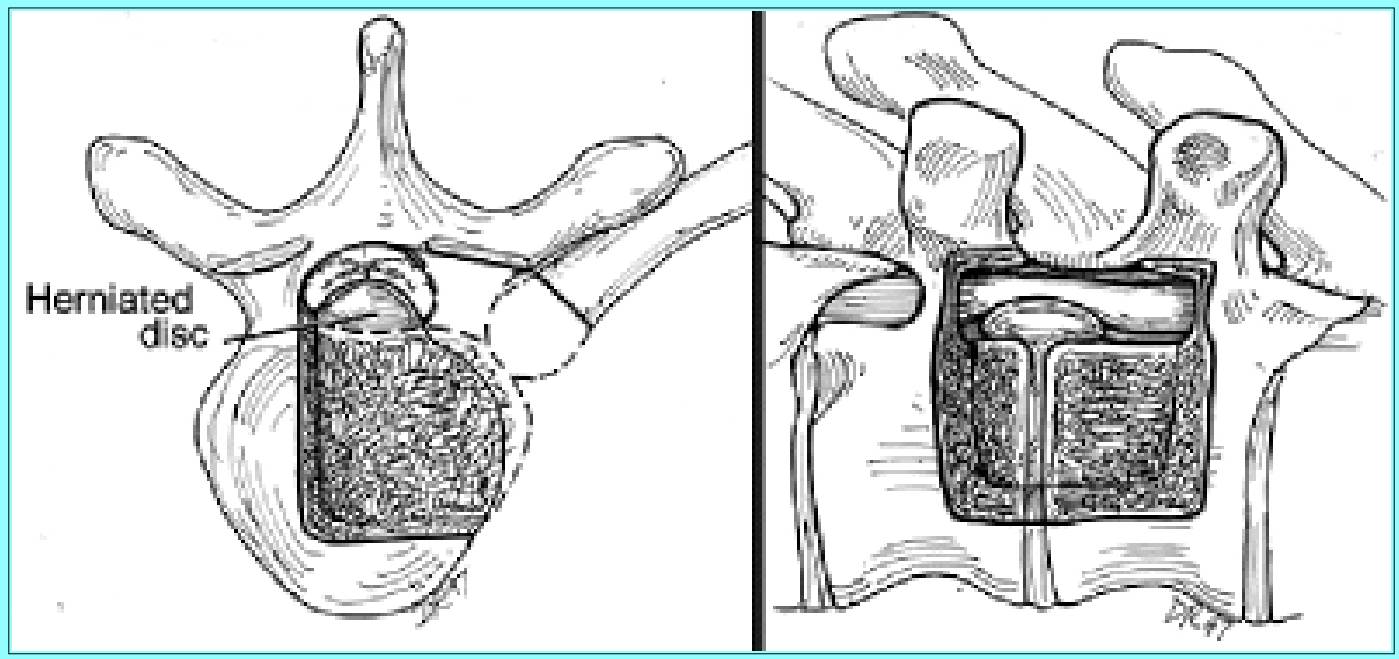

Fig. 4. Left: Illustration showing that a corpectomy is required to achieve adequate exposure and working space to remove large disc herniations. Right: Lateral view showing that the exposure must extend far enough to visualize normal dura above and below the disc.

Reconstruction and fusion of the spine are necessary after a corpectomy has been performed.

If the disc extended intradurally, a corpectomy was used to provide adequate exposure. The intradural disc material was grasped with a disc rongeur, and the disc was carefully separated from the arachnoid and pia mater with microdissectors (Figs. 5-8). The dura was sealed with fibrin glue and fascia. To prevent the formation of a cerebrospinal fluid (CSF)-pleural fistula, the chest tube was placed to water seal rather than suction. A lumbar drain or lumboperitoneal shunt was used to divert CSF and to reduce intraspinal pressure until the dural incision had sealed postoperatively. 


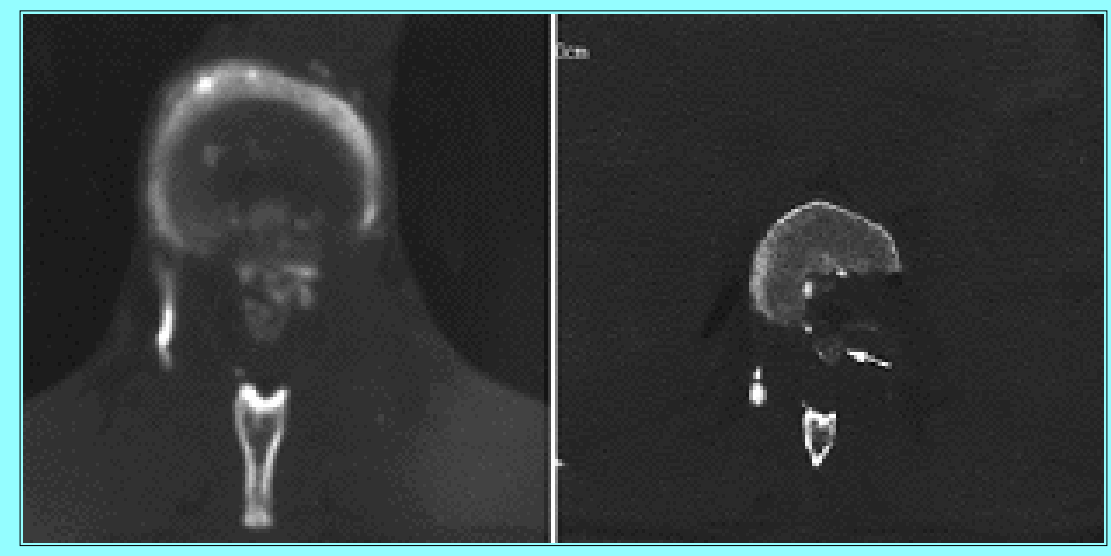

Fig. 5. Left: Preoperative CT scan demonstrating a large calcified disc at T10-11 compressing the spinal cord and causing severe, progressive myelopathy. A prior resection had been attempted unsuccessfully with a costotransversectomy. Right: Postoperative CT scan obtained after a thoracoscopic corpectomy was performed to expose and resect the densely calcified disc. Most of the disc material has been removed; however, a residual intradural calcified fragment (arrow), which was obscured intraoperatively by a fold of dura, remains. This residual disc fragment was removed without complications at a second thoracoscopic procedure, which was performed within 24 hours of the first thoracoscopic discectomy. Intraoperative photographs of the thoracoscopic removal of the residual fragment are shown in Figs. 6 and 7. 


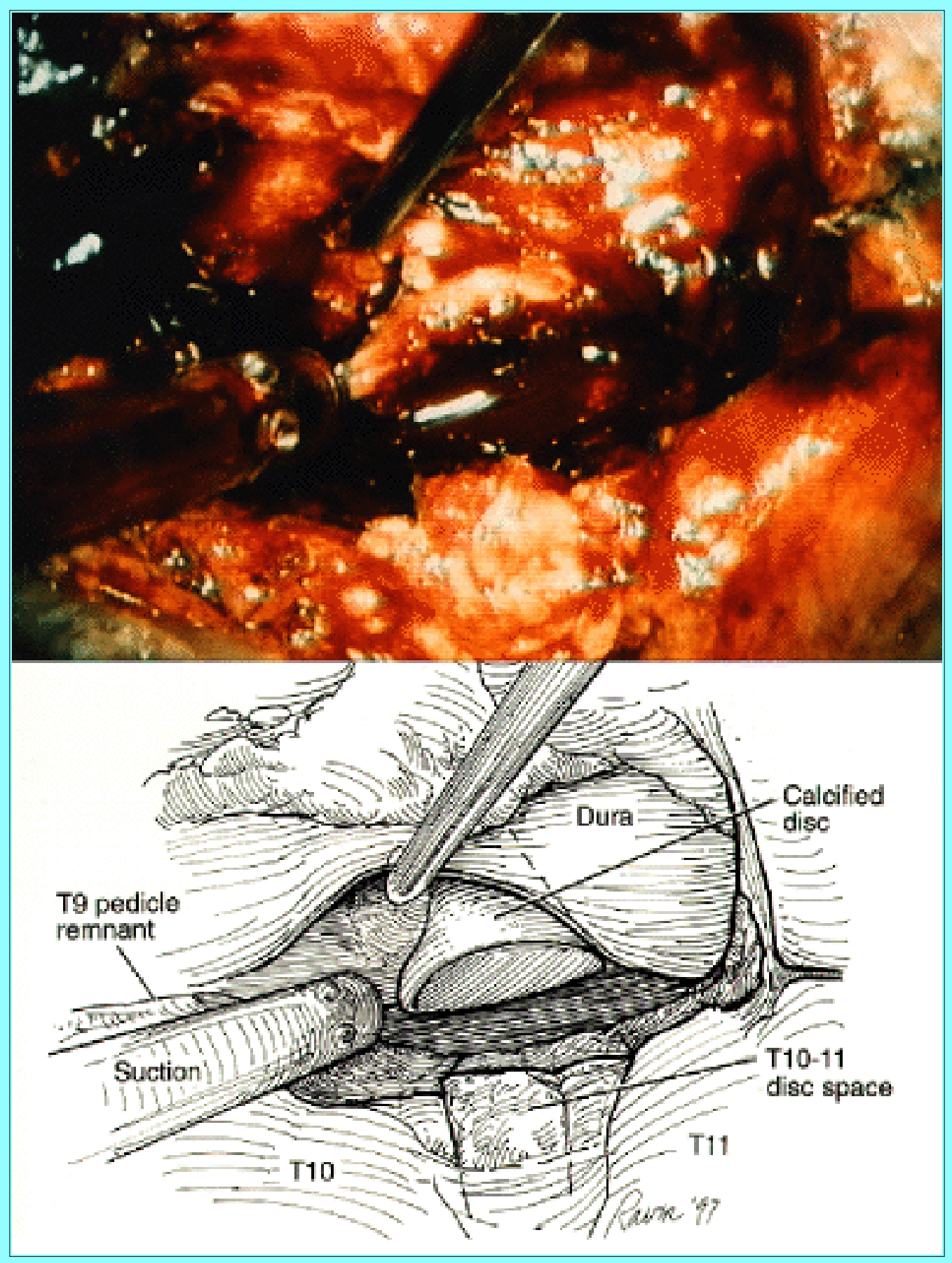

Fig. 6. Intraoperative thoracoscopic photograph (upper) and illustration (lower) showing a mushroom-shaped stalk of calcified disc material extending transdurally. Endoscopic microdissection tools are used to dissect the disc from the dural and pial surfaces. A nerve hook is used to retract the dural edges to visualize the intradural component of the disc. 


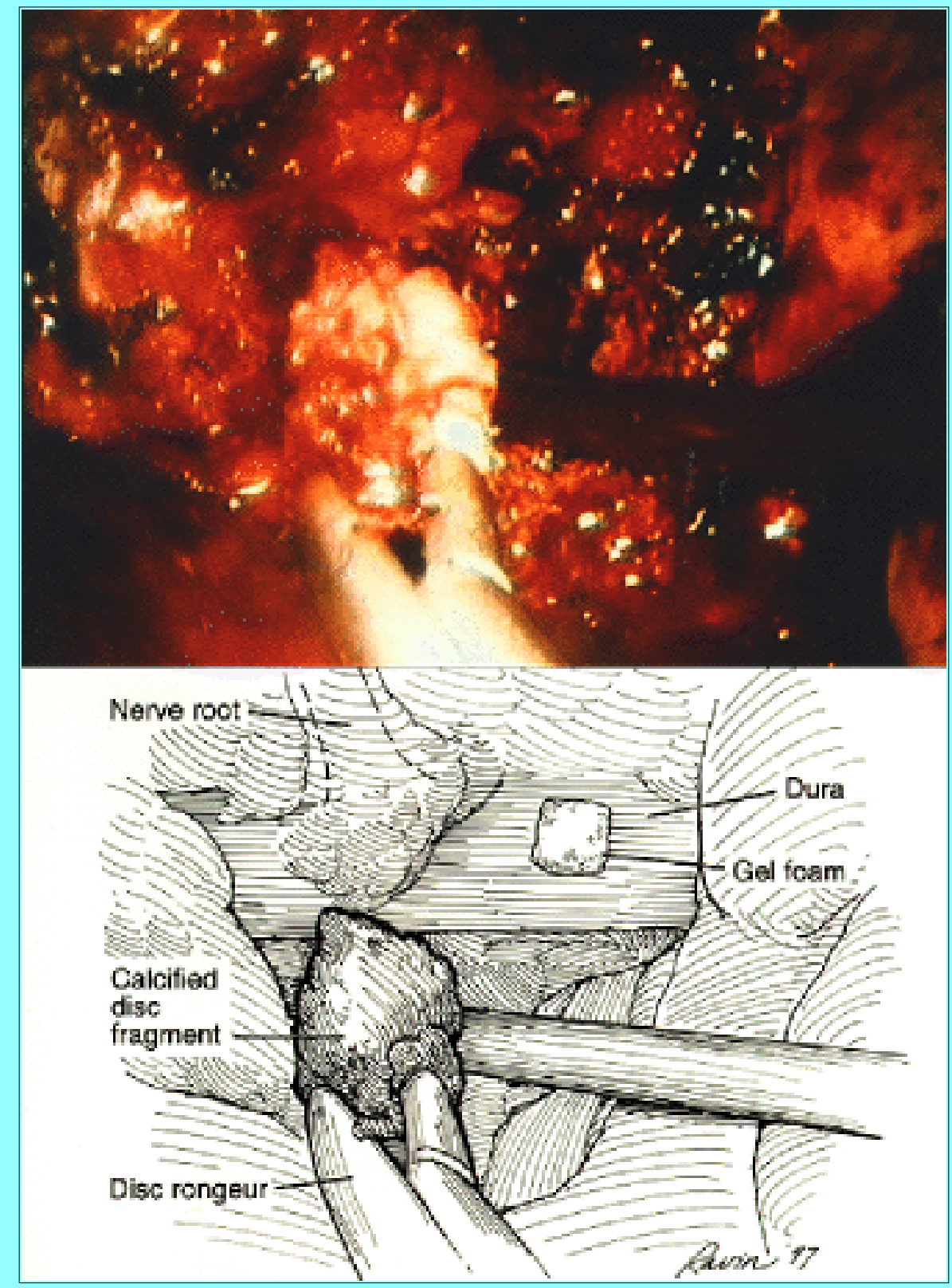

Fig. 7. Intraoperative thoracoscopic photograph (upper) and illustration (lower) showing the calcified intradural disc fragment being extracted and removed with a disc rongeur after it had been separated from the pial surface of the spinal cord. The dura is sealed with fibrin glue after the intradural fragment is extracted.
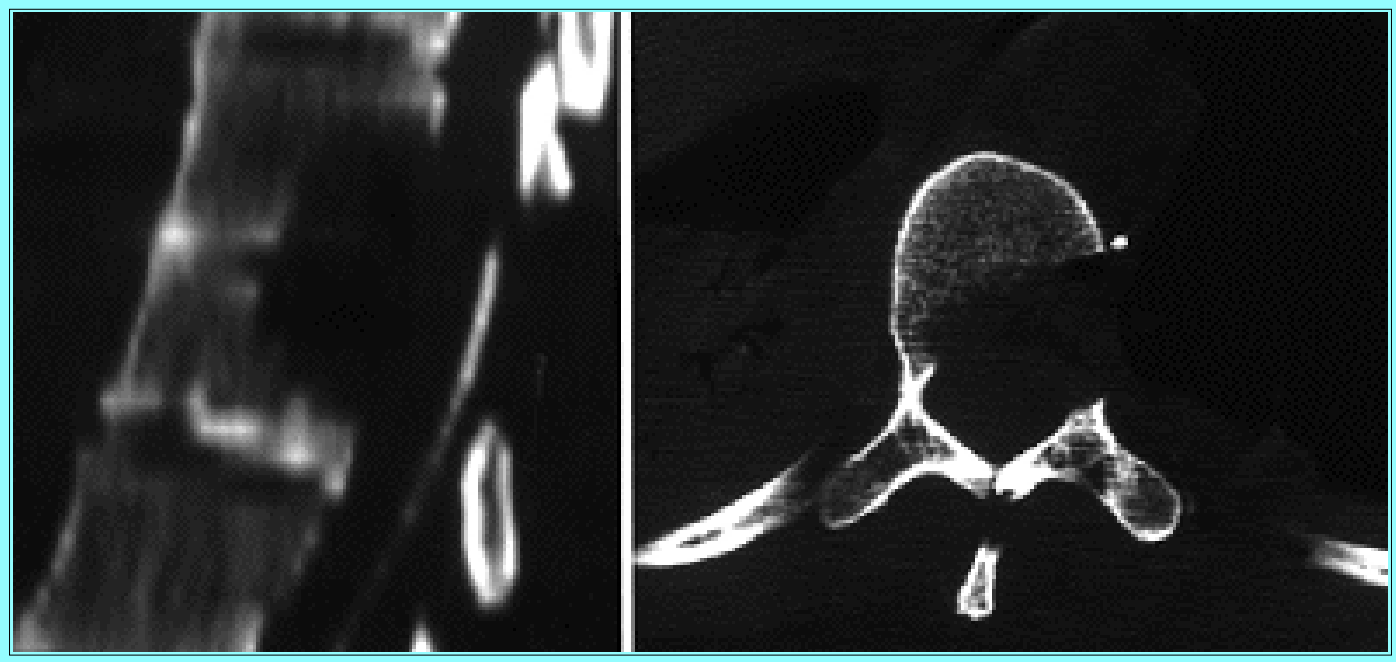
Fig. 8. Sagittal (left) and axial (right) CT scans obtained after complete resection of a calcified intradural disc. A lumbar drain was placed to prevent a subarachnoid-pleural fistula. The extent of the corpectomy required to expose the disc is demonstrated.

After the spinal cord was decompressed, the depth of the dissection was verified by using fluoroscopy. Epidural hemostasis was achieved; the chest was irrigated with antibiotic solution; disc material and bone debris were removed from the chest; the portals were removed; the chest tubes were inserted; the lung was reinflated; and the incisions were closed in a routine fashion. Postoperatively, the chest tubes remained in place until their output was less than $100 \mathrm{ml} / \mathrm{day}$.

All patients underwent serial chest radiography in the recovery room, on the 1st postoperative day, after the chest tubes were removed, and as needed. Patients with soft or calcified discs underwent magnetic resonance imaging and those with densely calcified discs underwent computerized tomography (CT) scanning to assess the extent of resection and decompression (Figs. 9 and 10).

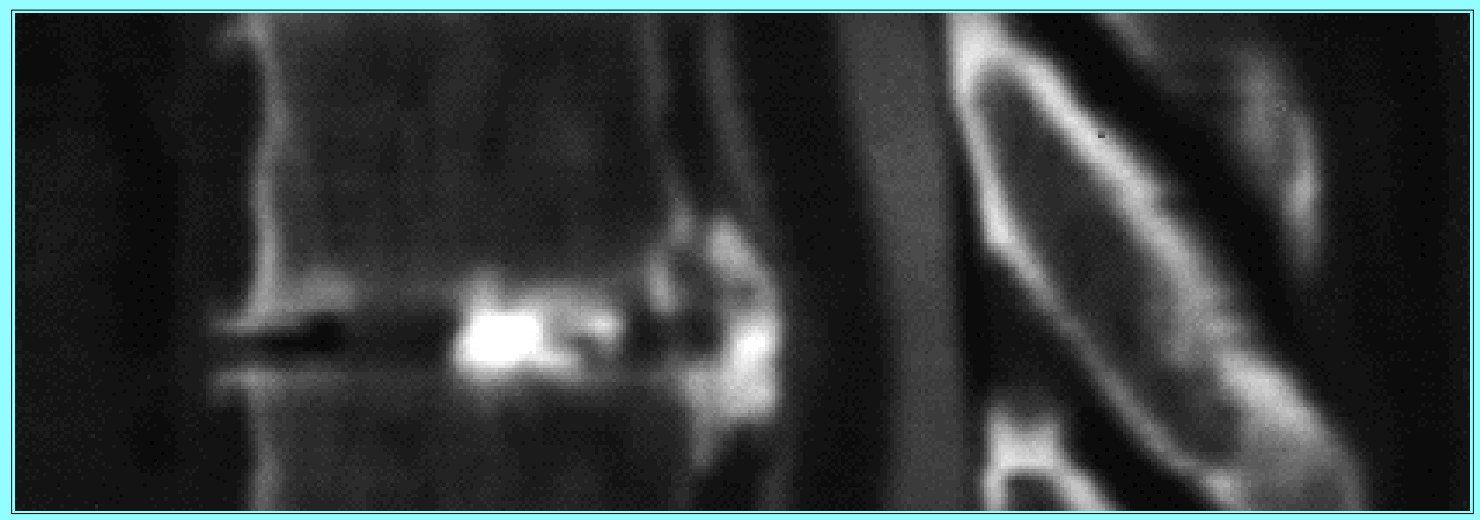

Fig. 9. Sagittal reconstructed CT scan obtained in a patient with myelopathy and a densely calcified, broad-based, central disc herniation at T8-9.
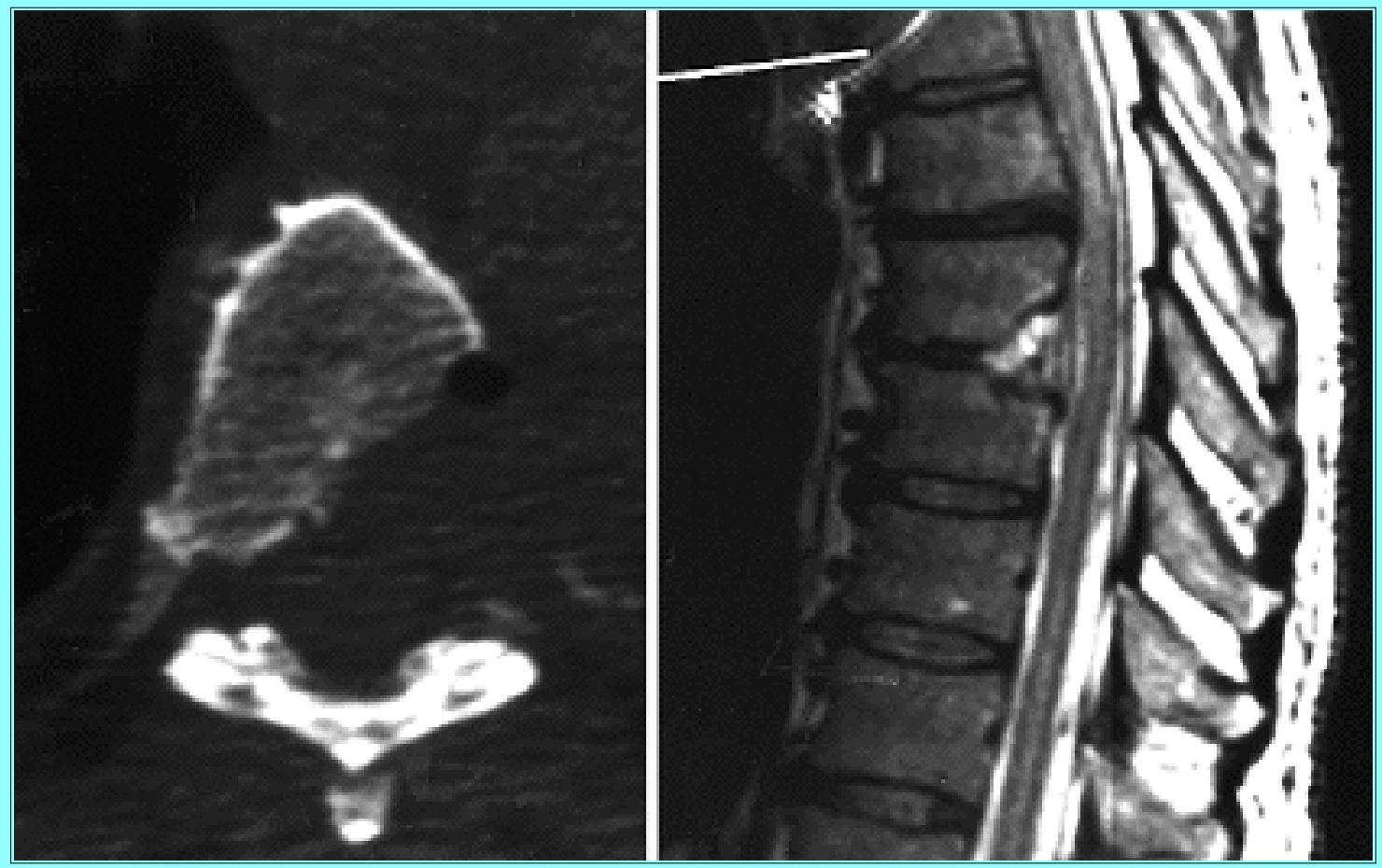

Fig. 10. Postoperative axial CT scan (left) and sagittal magnetic resonance image (right) obtained in the same patient as the scan shown in Fig. 9. A complete decompression has 
been achieved without complications. A pyramidal cavity was created to expose and resect the herniated disc.

Incidence rates were compared by performing a Z-test and analysis of variance. Operative data were compared using Tukey's test.

\section{RESULTS}

Most patients treated with thoracoscopic microdiscectomy underwent a single-level discectomy without reconstruction or fusion. Multilevel disc herniations required a two-level discectomy in 11 patients and a three-level discectomy in one patient. The locations of the disc herniations ranged from the T3-4 level to the T11-12 level. The vertebral levels most commonly involved were T6-7 and T9-10. In the 68 discectomies performed, there were 33 calcified or ossified discs and 35 soft discs; 65 of the discs were extradural and three had eroded transdurally. Corpectomies were required in six patients for treatment of intradural discs (three patients) or very large calcified discs (three patients).

Of the 55 patients who underwent thoracoscopy, 13 were referred for endoscopic treatment after having already undergone unsuccessful open surgery in an attempt to treat the thoracic disc herniations. These initial operations included a transpedicular approach in three patients; a transfacet pedicle-sparing approach in one patient; a costotransversectomy in seven patients; and a thoracotomy in two. During their first open operation, two of these patients had sustained spinal cord injuries that caused the procedures to be aborted. Most of the patients developed progressive myelopathy after their initial procedures.

The mean operative time for thoracoscopic microdiscectomy was 3 hours and 25 minutes (range 80-542 minutes) with a mean blood loss of $327 \mathrm{ml}$ (range 124-1500 ml; Table 1). Compared with thoracotomy, thoracoscopy required a mean of 1 hour less operative time $(\mathrm{p}<0.05)$. It also was associated with one-half of the blood loss, one-half of the duration of chest tube drainage, one-fifth of the parenteral narcotic usage, and less than one-half of the length of hospitalization $(\mathrm{p}<0.05)$. Compared with costotransversectomy, thoracoscopy required a mean of 1.25 fewer hours of operative time $(p<0.05)$. The blood loss and length of hospitalization associated with costotransversectomy were similar to those associated with thoracoscopy. 


\begin{tabular}{|c|c|c|c|}
\hline \multicolumn{4}{|c|}{$\begin{array}{c}\text { TABLE } 1 \\
\text { COMPARISON OF OPERATIYE DATA OBTANED IN PATIENTS WHO UNDERWENT } \\
\text { THORACOSCOPV, THORACOTOM, OR COSTOTRANSVERSECTOMV FOR } \\
\text { HERNIATED THORACK DISCS }\end{array}$} \\
\hline OpData & $\begin{array}{l}\text { Thorac oscopy } \\
\text { (55 pabents) }\end{array}$ & $\begin{array}{l}\text { Thoracotomy } \\
\text { [18 pati ents] }\end{array}$ & $\begin{array}{l}\text { Costotrans- } \\
\text { versectomy } \\
\text { [15 pati ents] }\end{array}$ \\
\hline $\begin{array}{l}\text { op time (min) } \\
\text { tood loss (ml) } \\
\text { duration of ohest } \\
\text { tube (days) }\end{array}$ & $\begin{array}{l}205(80-542) \\
327(124-1500) \\
1.5(0-6)\end{array}$ & $\begin{array}{l}268(210-690) \\
683(250-1200) \\
3.5(2.8-9.1)\end{array}$ & $\begin{array}{c}280(155-440) \\
350 \text { (200-900) } \\
\text { NA }\end{array}$ \\
\hline $\begin{array}{l}\text { narootic pain medi- } \\
\text { cation (mgiday) }\end{array}$ & $3.7(1.5-15)$ & $20.4(5-60)$ & $3.0(1.3-21)$ \\
\hline hospital stay (days) & $6.5(2-24)$ & $16.2(5-34)$ & $5.0(4-8)$ \\
\hline \multicolumn{4}{|c|}{$\begin{array}{l}\text { * Values are expressed as means with ranges shown parenthetically. Abbre- } \\
\text { viation: NA = not applicate. } \\
\dagger \text { Intravenous, intramuscular, or epidural analgesic medications. } \\
\ddagger \text { Two patients had pleural violations and required dhest tubes for } 2 \text { days post } \\
\text { operati vel } y\end{array}$} \\
\hline
\end{tabular}

\section{Surgical Complications}

Thoracoscopy. The surgical complications associated with thoracoscopy are listed in Table 2. Atelectasis was minimized by reinflating the lung for 5 to 10 minutes/hour of operative time. Both cases of hemothorax required evacuation using thoracoscopy for the reoperation. One case of hemothorax developed 1 week after surgery and appeared to be caused by bleeding from a segmental vein that had been incompletely ligated on the surface of the spine. The other case was caused by an intercostal artery at a portal site that bled when a chest tube was removed from the thorax. All intercostal neuralgias that occurred in patients after thoracoscopy were transient and resolved within 1 to 2 weeks. In two cases the disc level was misidentified radiographically. In both cases, the appropriate level was identified intraoperatively or in the recovery room and was remedied by immediately performing the discectomy at the correct level without sequelae.

\begin{tabular}{|lccc|}
\hline & \multicolumn{3}{c}{ TABLE 2 } \\
COMPARISON OF COMPLCATONS ASSOC ATED WITH THORACOSCOPV, \\
THORACOTOM, OR COSTOTRANSVESECTOMV FOR THORACK DISCS
\end{tabular}

Two patients had retained disc fragments after a thoracoscopic approach and required reoperations. In the patient who had undergone a prior costotransversectomy, a large stalk of calcified disc material hidden 
beneath a dural fold was recognized on postoperative CT scans obtained after the thoracoscopic procedure. The patient had no new neurological deficits, and the calcification was removed without complication during a second thoracoscopic procedure performed the next day (Figs. 5-8). The other patient was morbidly obese, and thick subpleural fat $(3 \mathrm{~cm})$ obscured the surface of the spine. A large herniated soft disc fragment was removed at surgery, but a large residual disc fragment had migrated cephalad within the spinal canal. Postoperatively, the patient deteriorated neurologically from Frankel Grade $\mathrm{C}$ to Grade B. The residual disc was identified on postoperative myelography and removed via a thoracotomy. The patient gradually recovered to Frankel Grade C.

Thoracotomy. Thoracotomy was associated with a significantly greater incidence of intercostal neuralgia than thoracoscopy ( $\mathrm{p}=0.009$; Table 2$)$. The neuralgia was also more prolonged and more severe than the mild transient intercostal neuralgia associated with thoracoscopy. The incidence of atelectasis and pulmonary complications was also significantly higher in cases treated by thoracotomy than those treated by thoracoscopy $(\mathrm{p}=0.016)$. The patients with chylothorax or hemothorax required reoperation for drainage, and the patient with pleural effusions was treated with bedside thoracentesis.

Costotransversectomy. Of the 15 patients who underwent costotransversectomy, two patients had pleural violations and required a chest tube for 24 to 48 hours after surgery. Two patients had residual discs that caused progressive myelopathy or persistent radicular symptoms; these patients required another operation. Other complications associated with costotransversectomy are listed in Table 2.

\section{Surgical Outcomes}

The clinical and neurological outcomes achieved in patients treated by thoracoscopy were excellent (Table 3). Patients with milder neurological deficits had more favorable functional recoveries than patients with severe deficits. Patients with severe myelopathies were more likely either to stabilize or to have residual neurological deficits. Among the 36 patients with myelopathy, 22 recovered normal neurological function. Five patients improved functionally with some residual myelopathic signs and symptoms, and the myelopathy was stabilized in nine patients. Among the 19 patients with isolated thoracic radiculopathies, radicular pain completely resolved in 15 and was moderately improved in four. No patients had worsened radicular pain. The mean follow-up period was 15 months (range 6-45 months).

\begin{tabular}{|c|c|c|c|c|c|}
\hline OUTC & 5 & $\mathrm{~T} / \mathrm{A}$ & $T_{1}$ & 0 & \\
\hline & & p & ad & tie & \\
\hline Franke Gra de & $A$ & B & $\mathrm{C}$ & $\mathrm{D}$ & $E$ \\
\hline $\begin{array}{l}\mathrm{A} \\
\mathrm{B} \\
\mathrm{C} \\
\mathrm{D} \\
\mathrm{E}\end{array}$ & $\begin{array}{l}0 \\
0 \\
0 \\
0 \\
0\end{array}$ & $\begin{array}{l}0 \\
1 \\
0 \\
0 \\
0\end{array}$ & $\begin{array}{l}0 \\
0 \\
2 \\
0 \\
0\end{array}$ & $\begin{array}{l}0 \\
0 \\
5 \\
6 \\
0\end{array}$ & $\begin{array}{r}0 \\
0 \\
0 \\
22 \\
19\end{array}$ \\
\hline $\begin{array}{l}{ }^{*} \text { Frankel grao } \\
\text { normal neurolo }\end{array}$ & & & & & \\
\hline
\end{tabular}

On long-term follow-up evaluation, no patient has exhibited recurrent radicular pain, progressive myelopathy, or evidence of postoperative instability. All patients who had corpectomies underwent prophylactic adjunctive spinal reconstruction with bone grafts and spinal fixation. None of these patients 
has developed nonunion.

\section{DISCUSSION}

\section{Surgical Indications for Thoracic Discectomy}

Surgical treatment is required for herniated thoracic discs that cause neurological symptoms from compression of the spinal cord or thoracic spinal nerves. Myelopathy is the strongest indication for surgery to prevent further permanent damage to the spinal cord. Prolonged, disabling, severe, thoracic radicular pain that is refractory to medical therapy is another primary indication for surgery.

\section{Selecting an Operative Approach}

The following primary approaches have been advocated for the treatment of herniated thoracic discs: the posterior transpedicular approach and its variants, $[2,27,36,44]$ the posterolateral approach and its variants, $[2,5,8,16,19,26,32]$ and the anterior transthoracic approach (thoracotomy or thoracoscopy).[4,5,11,18,31,35,37,38,42,43] Laminectomy alone is not advocated for the treatment of herniated thoracic discs because it is associated with a high incidence of neurological deterioration. $[3,7,19,28,44,45]$

The posterior and posterolateral approaches have been relatively popular among neurosurgeons for the treatment of thoracic disc herniations because the approaches are familiar and the surgeon can work independently. These approaches are particularly suitable for removal of disc material if a thoracic disc herniation is small, focal, soft, and located laterally in the spinal canal. Their main limitation is that the surgeon is unable to see the ventral surface of the dura during the dissection. The posterior or posterolateral approaches are poorly suited for large, central, broad-based, or densely calcified thoracic discs, especially when there is substantial ventral infolding of the dura and distortion of the spinal cord or intradural penetration of the disc. In these circumstances, an anterior approach is needed so that the surgeon can completely visualize and expose the dura, with adequate space to work and manipulate the surgical tools.

Thoracotomy. Several strong advocates of thoracotomy for the treatment of thoracic discs have emphasized that this technique is the only route that provides adequate, unrestricted exposure to work and to visualize the ventral surface of the spinal cord, which is essential for the safe resection of large thoracic disc herniations. [5,35,37,38,43] However, the popularity of thoracotomy has been tempered by the need for another surgeon to provide access; the complications associated with the procedure (postthoracotomy pain syndromes); $[9,14,34]$ and surgeons' relative unfamiliarity with ventral operative techniques for anterior thoracic discectomy.

Thoracoscopic Microdiscectomy. Thoracic surgeons developed thoracoscopy as an alternative to thoracotomy to reduce the approach-related incidences of morbidity associated with the anterior transthoracic exposure.[1,8,11,12,15,17,18,20,23-25,30,31,33,39,42] In thoracoscopy (microsurgical endoscopy), small portal incisions in the intercostal spaces are used to access the thoracic cavity without retracting the ribs or widely separating the superficial tissues of the thorax. The portals are used to insert the endoscope and tools for dissection after exposure has been achieved by deflating one lung. Thoracoscopy has been an effective approach for the treatment of a broad range of pathological processes affecting the thorax and mediastinum.[1,8,20,23,25,30,31]

Although this is not a prospective, randomized study, our clinical experience with thoracoscopic 
microdiscectomy has demonstrated that the technique can reduce the approach-related incidences of morbidity associated with the anterior transthoracic routes. Thoracoscopy minimally disrupts the soft tissues of the chest and avoids rib retraction. Yet, it provides extensive access to the inside of the thorax, permitting surgery to be performed in a wide space.

In experienced hands, thoracoscopy can be performed safely and effectively to remove thoracic disc herniations. It provides a microsurgical view of the entire ventral surface of the spine and spinal cord. Compared with thoracotomy, thoracoscopy provides identical visualization and exposure of the spine, with significantly fewer incidences of operative morbidity, less pain, fewer pulmonary problems, and shorter hospitalizations. [10,13,15,24,39,41] Compared with posterolateral approaches to the thoracic spine, thoracoscopy provides more complete visualization and access to the ventral spine and spinal cord, and enables more complete resection of midline discs and calcified discs.

The clinical utility of thoracoscopy for discectomy, anterior release of spinal deformities, corpectomy, and thoracic spinal reconstruction has already been demonstrated.[11-13,18,33,41] The technique also can be used effectively for sympathectomy, biopsy, tumor resection, infection debridement, and intrathoracic nerve sheath tumor resection.[10,21,22,29,33,40,41,46] Thoracoscopy, however, is a very technically demanding procedure. It requires extensive skill and dedicated practice in the laboratory to learn and master the new psychomotor skills that are required to perform the procedure safely. Dedicated laboratory training is mandatory before surgeons attempt these techniques clinically.

\section{References}

1. Allen MS, Deschamps C, Jones DM, et al: Video-assisted thoracic surgical procedures: the Mayo experience. Mayo Clin Proc 71:351-359, 1996

2. Arce CA, Dohrmann GJ: Thoracic disc herniation. Improved diagnosis with computed tomographic scanning and a review of the literature. Surg Neurol 23:356-361, 1985

3. Arseni C, Nash F: Thoracic intervertebral disc protrusion: a clinical study. J Neurosurg 17:418-430, 1960

4. Benjamin V: Diagnosis and management of thoracic disc disease. Clin Neurosurg 30:577-605, 1983

5. Bohlman HH, Zdeblick TA: Anterior excision of herniated thoracic discs. J Bone Joint Surg (Am) 70:1038-1047, 1988

6. Broc GG, Crawford NR, Sonntag VKH, et al: Biomechanical effects of transthoracic microdisectomy. Spine 22:605-612, 1997

7. Chou SN, Seljeskog EL: Alternative surgical approaches to the thoracic spine. Clin Neurosurg 20:306-321, 1973

8. Coltharp WH, Arnold JH, Alford WC Jr, et al: Videothoracoscopy: improved technique and expanded indications. Ann Thorac Surg 53:776-779, 1992

9. Dajczman E, Gordon A, Kreisman H, et al: Long-term postthoracotomy pain. Chest 99:270-274, 1991

10. Dickman CA, Karahalios DG: Thoracoscopic spinal surgery. Clin Neurosurg 43:392-422, 1996 
11. Dickman CA, Mican C: Thoracoscopic approaches for the treatment of anterior thoracic spinal pathology. BNI Q 12:4-19, 1996

12. Dickman CA, Mican CA: Multilevel anterior thoracic discectomies and anterior interbody fusion using a microsurgical thoracoscopic approach. Case report. J Neurosurg 84:104-109, 1996

13. Dickman CA, Rosenthal D, Karahalios DG, et al: Thoracic vertebrectomy and reconstruction using a microsurgical thoracoscopic approach. Neurosurgery 38:279-293, 1996

14. Faciszewski T, Winter RB, Lonstein JE, et al: The surgical and medical perioperative complications of anterior spinal fusion surgery in the thoracic and lumbar spine in adults. A review of 1223 procedures. Spine 20:1592-1599, 1995

15. Ferson PF, Landreneau RJ, Dowling RD, et al: Comparison of open versus thoracoscopic lung biopsy for diffuse infiltrative pulmonary disease. J Thorac Cardiovasc Surg 106: 194-199, 1993

16. Fessler RG, Dietze DD Jr, Mac Millan M, et al: Lateral parascapular extrapleural approach to the upper thoracic spine. J Neurosurg 75:349-355, 1991

17. Hazelrigg SR, Landreneau RJ, Boley TM, et al: The effect of muscle-sparing versus standard posterolateral thoracotomy on pulmonary function, muscle strength, and postoperative pain. J Thorac Cardiovasc Surg 101:394-401, 1991

18. Horowitz MB, Moossy JJ, Julian T, et al: Thoracic discectomy using video assisted thoracoscopy. Spine 19:1082-1086, 1994

19. Hulme A: The surgical approach to thoracic intervertebral disc protrusions. J Neurol Neurosurg Psychiatry 23:133-137, 1960

20. Kaiser LR: Video-assisted thoracic surgery. Current state of the art. Ann Surg 220:720-734, 1994

21. Kao MC, Tsai JC, Lai DM, et al: Autonomic activities in hyperhidrosis patients before, during, and after endoscopic laser sympathectomy. Neurosurgery 34:262-268, 1994

22. Landreneau RJ, Dowling RD, Ferson PF: Thoracoscopic resection of a posterior mediastinal neurogenic tumor. Chest 102:1288-1290, 1992

23. Landreneau RJ, Hazelrigg SR, Ferson PF, et al: Thoracoscopic resection of 85 pulmonary lesions. Ann Thorac Surg 54:415-420, 1992

24. Landreneau RJ, Hazelrigg SR, Mack MJ, et al: Postoperative pain-related morbidity: video-assisted thoracic surgery versus thoracotomy. Ann Thorac Surg 56:1285-1289, 1993

25. Landreneau RJ, Mack MJ, Hazelrigg SR, et al: Video-assisted thoracic surgery: basic technical concepts and intercostal approach strategies. Ann Thorac Surg 54:800-807, 1992

26. Larson SJ, Holst RA, Hemmy DC, et al: Lateral extracavitary approach to traumatic lesions of the thoracic and lumbar spine. J Neurosurg 45:628-637, 1976

27. Le Roux PD, Haglund MM, Harris AB: Thoracic disc disease: experience with the transpedicular approach in twenty consecutive patients. Neurosurgery 33:58-66, 1993 
28. Love JG, Schorn VG: Thoracic-disk protrusions. JAMA 191:627-631, 1965

29. Lyons MK, Gharagozloo F: Video-assisted thoracoscopic resection of intercostal neurofibroma. Surg Neurol 43:542-545, 1995

30. Mack MJ, Aronoff RJ, Acuff TE, et al: Present role of thoracoscopy in the diagnosis and treatment of diseases of the chest. Ann Thorac Surg 54:403-409, 1992

31. Mack MJ, Regan JJ, Bobechko WP, et al: Application of thoracoscopy for diseases of the spine. Ann Thorac Surg 56:736-738, 1993

32. Maiman DJ, Larson SJ, Luck E, et al: Lateral extracavitary approach to the spine for thoracic disc herniation: report of 23 cases. Neurosurgery 14:178-182, 1984

33. McAfee PC, Regan JR, Zdeblick T, et al: The incidence of complications in endoscopic anterior thoracolumbar spinal reconstructive surgery. A prospective multicenter study comprising the first 100 consecutive cases. Spine 20:1624-1632, 1995

34. Naunheim KS, Barnett MG, Crandall DG, et al: Anterior exposure of the thoracic spine. Ann Thorac Surg 57:1436-1439, 1994

35. Otani K, Nakai S, Fujimura Y, et al: Surgical treatment of thoracic disc herniation using the anterior approach. J Bone Joint Surg (Br) 64:340-343, 1982

36. Patterson RH Jr, Arbit E: A surgical approach through the pedicle to protruded thoracic discs. J Neurosurg 48:768-772, 1978

37. Perot PL Jr, Munro DD: Transthoracic removal of midline thoracic disc protrusions causing spinal cord compression. J Neurosurg 31:452-458, 1969

38. Ransohoff J, Spencer F, Siew F, et al: Transthoracic removal of thoracic disc. Report of three cases. J Neurosurg 31:459-461, 1969

39. Regan JJ, Mack MJ, Picetti GD III, et al: A comparison of video-assisted thoracoscopic surgery (VATS) with open thoracotomy in thoracic spinal surgery. Todays Ther Trends 11:203-218, 1994

40. Robertson DP, Simpson RK, Rose JE, et al: Video-assisted endoscopic thoracic ganglionectomy. J Neurosurg 79:238-240, 1993

41. Rosenthal D, Dickman C, Lorenz R, et al: Thoracic disc herniation: early results after surgical treatment using microsurgical endoscopy. J Neurosurg 84:334A, 1996 (Abstract)

42. Rosenthal D, Rosenthal R, de Simone A: Removal of a protruded thoracic disc using microsurgical endoscopy. A new technique. Spine 19:1087-1091, 1994

43. Sekhar LN, Jannetta PJ: Thoracic disc herniation: operative approaches and results. Neurosurgery 12:303-305, 1983

44. Stillerman CB, Chen TC, Day JD, et al: The transfacet pedicle-sparing approach for thoracic disc removal: cadaveric morphometric analysis and preliminary clinical experience. J Neurosurg 83:971-976, 1995 
45. Stillerman CB, Weiss MH: Principles of approaches to the thoracic spine, in Tarlov EC (ed): Neurosurgical Treatment of Disorders of the Thoracic Spine. AANS Neurosurgical Topics Series. Park Ridge, Ill: American Association of Neurological Surgeons, 1991, pp 1-18

46. Weder W, Schlumpf R, Schimmer R, et al: Thoracoscopic resection of benign schwannoma. Thorac Cardiovasc Surg 40:192-194, 1992

Manuscript received December 16, 1997.

Accepted in final form March 24, 1998.

Address reprint requests to: Curtis A. Dickman, M.D., c/o Neuroscience Publications, Barrow Neurological Institute, 350 West Thomas Road, Phoenix, Arizona 85013-4496. email: neuropub@mha.chw.edu. 